\title{
Advances in WNK Signaling of Salt and Potassium Metabolism: Clinical Implications
}

\author{
Juan Pablo Arroyo ${ }^{a, b}$ Gerardo Gamba ${ }^{a}$, \\ ${ }^{a}$ Department of Nephrology and Mineral Metabolism, Instituto Nacional de Ciencias Médicas y Nutrición Salvador \\ Zubirán, and ${ }^{\mathrm{b}}$ Molecular Physiology Unit, Instituto de Investigaciones Biomédicas, Universidad Nacional Autónoma \\ de México, Mexico City, Mexico
}

\section{Key Words}

Angiotensin II - Electrolytes - Hypertension • Potassium • Sodium

\begin{abstract}
Recent evidence due to the discovery of a family of kinases implicated in arterial hypertension now points to the underlying molecular mechanisms that dictate $\mathrm{Na}^{+}, \mathrm{K}^{+}$and water handling in the nephron. These new key players need to be understood in order to fully comprehend the pathophysiology, manifestations, and treatment of common clinical entities such as hypovolemic shock, congestive heart failure, primary hyperaldosteronism, nephrotic syndrome and hypertension. It is through the analysis of the volume status and electrolyte abnormalities that commonly present with these diseases that we can begin to create a link between the abstract concept of a kinase regulation and how a patient will respond to a particular treatment. This review is an attempt to bridge that gap.

Copyright $\odot 2012$ S. Karger AG, Basel
\end{abstract}

The balance of $\mathrm{Na}^{+}$and $\mathrm{K}^{+}$involve the intracellular and extracellular distribution of these ions. The $\mathrm{Na}^{+} / \mathrm{K}^{+}$ ATPase distributes these ions such that $\mathrm{Na}^{+}$is the most abundant extraceullar ion and $\mathrm{K}^{+}$is the most abundant intracellular ion. Variations in $\mathrm{Na}^{+}$and water affect volume status. Low sodium intake activates volume retention mechanisms necessary to maintain extracellular volume, while the excess of salt and water in physiological conditions is excreted by pressure natriuresis, or in pathological situations results in the formation of edema. In contrast, distribution of $\mathrm{K}^{+}$is in direct relation to dietary intake, intracellular handling, and urinary flow rate. Dietary intake is generally not a cause of alterations in plasma $\mathrm{K}^{+}$. Occasionally, altered handling of $\mathrm{K}^{+}$by cells (e.g. rhabdomyolysis) can lead to hyperkalemia and the development of cardiac arrhythmias and death. Urinary flow rate, however, is the major determinant of the kidney's ability to successfully excrete $\mathrm{K}^{+}$, in such a way that high urinary flow rate favors $\mathrm{K}^{+}$excretion, while low urinary flow leads to $\mathrm{K}^{+}$retention. How the recently discovered With No Lysine (K) kinases (WNKs) are involved in the regulation of the ion transport systems in the distal nephron has become an area of intense research in the past years [for extensive reviews, see 1,2].

\begin{tabular}{lll}
\hline KARGER & (c) 2012 S. Karger AG, Basel & Gerardo Gamba \\
Fax +41613061234 & $0250-8095 / 12 / 0354-0379 \$ 38.00 / 0$ & Vasco de Quiroga No. 15 \\
$\begin{array}{l}\text { E-Mail karger@karger.ch } \\
\text { www.karger.com }\end{array}$ & Accessible online at: & Tlalpan, Mexico City 14000 (Mexico) \\
www.karger.com/ajn & Tel. +52 55 5513 38 68 \\
E-Mail gamba @ biomedicas.unam.mx
\end{tabular}


The WNKs are a group of serine/threonine kinases which have been associated with the development of hypertension in humans [3]. Intronic deletions of the WNK1 gene leading to over expression of an otherwise normal WNK1, or missense mutations of the WNK4 gene in a highly conserved acidic region, are the cause of an inherited form of salt sensitive hypertension known as pseudohypoaldosteronism type II (PHA II; also known as familial hyperkalemic hypertension or Gordon syndrome) [3]. This is a rare autosomal dominant disease featuring arterial hypertension, hyperkalemia, and metabolic acidosis $[4,5]$. The PHA II clinical picture is the exact mirror image of Gitelman's disease, an autosomal-recessive syndrome featuring hypokalemic metabolic alkalosis with arterial hypotension, that is due to inactivating mutations of the renal thiazide-sensitive $\mathrm{Na}-\mathrm{Cl}$ cotransporter (NCC) $[6,7]$ located in the distal convoluted tubule (DCT) [810]. The fact that these syndromes mirror each other and the clinical observation that PHA II can be corrected by low doses of thiazides [4], led to the proposal that the modulation of NCC by the WNKs could be underlying the pathophysiology of PHA II [11]. Observations from the past few years proved this hypothesis and revealed an important role for WNKs that not only helps explain PHA II, but also helps clarify the molecular nature of salt and/or potassium handling in physiological circumstances and in common clinical syndromes such as congestive heart failure, hypovolemia, primary hyperaldosteronism and hyperkalemia.

The mineralocorticoid hormone aldosterone has been considered for many years a key player in the modulation of $\mathrm{Na}^{+}$and $\mathrm{K}^{+}$transport systems in the distal nephron. Owing to the discovery of WNK kinases, the exact mechanism through which the kidneys are able to carry out different responses to hyperkalemia or hypovolemia, conditions in which aldosterone is elevated, has only recently begun to be elucidated. Aldosterone is secreted when salt needs to be retained (low salt diet/hypovolemia) or when potassium has to be excreted (high potassium diet/hyperkalemia). During volume depletion, the reabsorption of salt is increased, but potassium secretion remains unchanged, allowing for salt retention, without potassium loss. In contrast, during hyperkalemia, potassium secretion is favored in the distal nephron, without greatly modifying the salt reabsorption rate. Thus, potassium is excreted without retaining salt. How the kidneys are able to carry out two distinct physiological responses in two different situations (hypovolemia vs. hyperkalemia) in which aldosterone is increased is known as the aldosterone paradox [12]. How does the kidney recognize the difference between these two states? As we discuss below, it seems likely that what explains how the kidney responds to these two states is the presence or absence of angiotensin II (Ang II), which is elevated in hypovolemia, but not in hyperkalemia, and its regulatory effects on ion transport pathways via WNK4 in the distal nephron.

The distal nephron is defined as the portion of the tubule that is located beyond the macula densa [13]. Changes in salt transport rate in the distal nephron can no longer be compensated by the tubuloglomerular feedback mechanism and thus, have a major effect on salt excretion in the urine. The distal nephron is composed of the DCT, the connecting tubule (CNT) and the collecting duct (CD). The CD receives the fluid from several DCT/CNT segments. Thus, there are many more DCT/CNTs than CDs in the kidney. The DCT can be subdivided into early (DCT1) and late (DCT2) portions based on protein expression and histological differences [13-15]. Sodium transport pathways in the distal nephron include NCC, which is the target of thiazide-type diuretics, exclusively expressed in the DCT $[14,16]$, and the epithelial sodium channel $(\mathrm{ENaC})$, the target of amiloride, which is expressed in DCT2 and along the CNT and CD $[14,15,17]$. The $\mathrm{K}^{+}$transport pathways include the renal outer medullary potassium channels, ROMK, and the flow-dependent large $\mathrm{Ca}^{2+}$-activated potassium channels (BK channels), both of which are expressed throughout the distal nephron [18-20]. WNK1 and WNK4 span the entire distal nephron. There is, however, a short, kidney specific isoform of WNK1 (KS-WNK1), which lacks the kinase domain, that is strategically expressed only in the DCT (see below) [3, 14, 21, 22]. Additionally, another group of serine/threonine kinases known as the STE20-related proline-alanine-rich kinase SPAK and oxidative stress element 1, OSR1 have been shown to lie downstream of WNKs $[23,24]$. SPAK and OSR1 are present in the thick ascending limb of Henle and also in the DCT [25] and activation of SPAK/OSR1 by WNKs modulates the interaction/phosphorylation of these kinases with target transporters.

Owing to these expression patterns, there is a clear and understandable relationship between sodium reabsorption and potassium secretion in the distal nephron. Beyond the DCT, in the CNT/CD, potassium secretion is favored by increased flow and sodium reabsorption (fig. 1). This is because the entrance of $\mathrm{Na}^{+}$through $\mathrm{ENaC}$, generates a lumen negative voltage that favors $\mathrm{K}^{+}$secretion through ROMK [19]. Thus, in order to increase potassium secretion, the delivery of sodium to CNT/CD must be increased. This is achieved by inhibiting the up- 


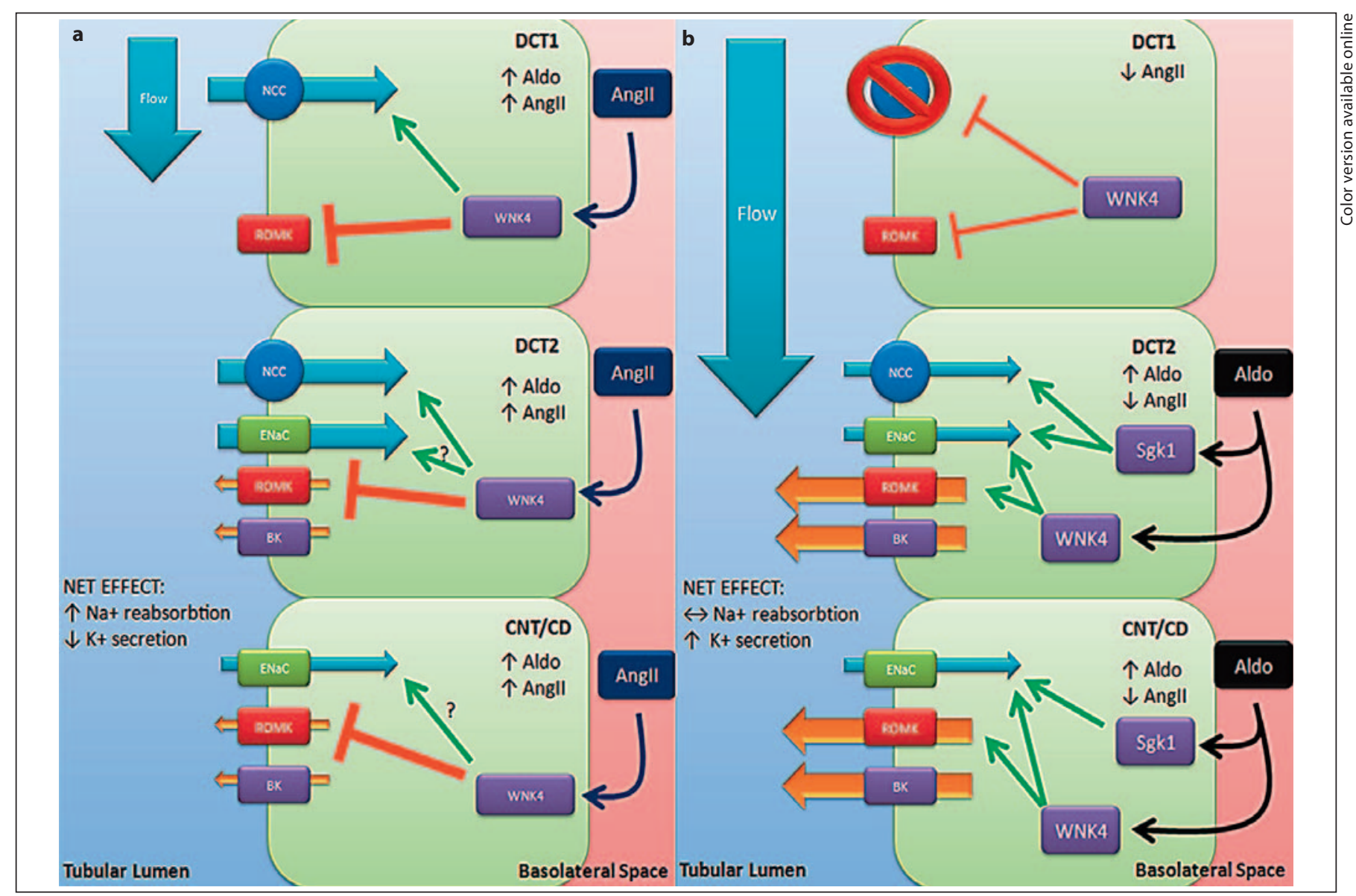

Fig. 1. a During hypovolemia, the increase in Ang II modifies WNK4 activity so that it stimulates NCC and $\mathrm{ENaC}$, while inhibiting ROMK. The stimulation of NCC in DCT1 significantly reduces urinary flow along the distal portions of the nephron, thus minimizing $\mathrm{K}^{+}$secretion. b During hyperkalemia, however, the presence of aldosterone in the absence of Ang II leads to an inhibited NCC in the aldosterone insensitive DCT1, and an increase in $\mathrm{ENaC}$ and ROMK from the aldosterone sensitive DCT2 and onward. The decreased salt reabsorption in DCT1 increases urinary flow to CNT/CD favoring $\mathrm{K}^{+}$excretion. stream salt reabsorption transporter NCC in the early DCT [26]. Additionally, increased fluid delivery to CNT/ CD will also activate BK channels [27]. It is for these reasons that increased salt and volume delivery to CNT/CD by loop or thiazide diuretics ( $\mathrm{K}^{+}$wasting) increase urinary potassium excretion, while the $\mathrm{K}^{+}$-sparing diuretics, such as amiloride that block $\mathrm{ENaC}$, indirectly prevent $\mathrm{K}^{+}$ secretion $[6,28,29]$. This interrelation of sodium and potassium handling of the distal nephron also explains the beneficial effect of the Dietary Approaches to Stop Hypertension (DASH) trial $[30,31]$ in which the best combination to prevent or improve hypertension is the low salt/ high potassium diet, because in order to excrete the potassium excess, salt reabsorption in the DCT must be reduced, thus increasing the renal salt excretion [32]. This exact phenomenon was observed by Palmer's group while studying in rats the effects of low $\mathrm{Na}^{+}$diet with normal $\mathrm{K}^{+}$versus a low $\mathrm{Na}^{+}$diet with low $\mathrm{K}^{+}$. In the low $\mathrm{K}^{+}$group, NCC protein expression increased dramatically, thus decreasing the distal delivery of salt and $\mathrm{Na}^{+}$and inhibiting $\mathrm{K}^{+}$secretion [33].

During normovolemia WNK4 purportedly behaves as an inhibitor of NCC, ENaC, and ROMK $[11,34,35]$. PHA II mutations alter the way in which WNK4 regulates these transport systems. NCC and ENaC are no longer inhibited, and thus, presumably activated, while the inhibition of ROMK is further increased by mutant WNK4 [11, 34-36]. This increases salt reabsorption while minimizing $\mathrm{K}^{+}$secretion, which explains the hypertension and hyperkalemia that characterize the PHA II pheno- 
Fig. 2. a In physiological conditions in the DCT1, the short KS-WNK1 isoform expression is severalfold higher than the long-WNK1 variant. Thus, KS-WNK1 prevents the WNK1-induced inhibition of WNK4, and thus allowing WNK4 to freely inhibit NCC and ROMK. b In contrast, in PHAII due to intronic deletions of the WNK1, the increased expression of the long-WNK1 variant overcomes the inhibition by KS-WNK1 leading to NCC activation, and ROMK inhibition, as a consequence of WNK4 inhibition by WNK1. In addition, the long WNK1 directly inhibits ROMK.

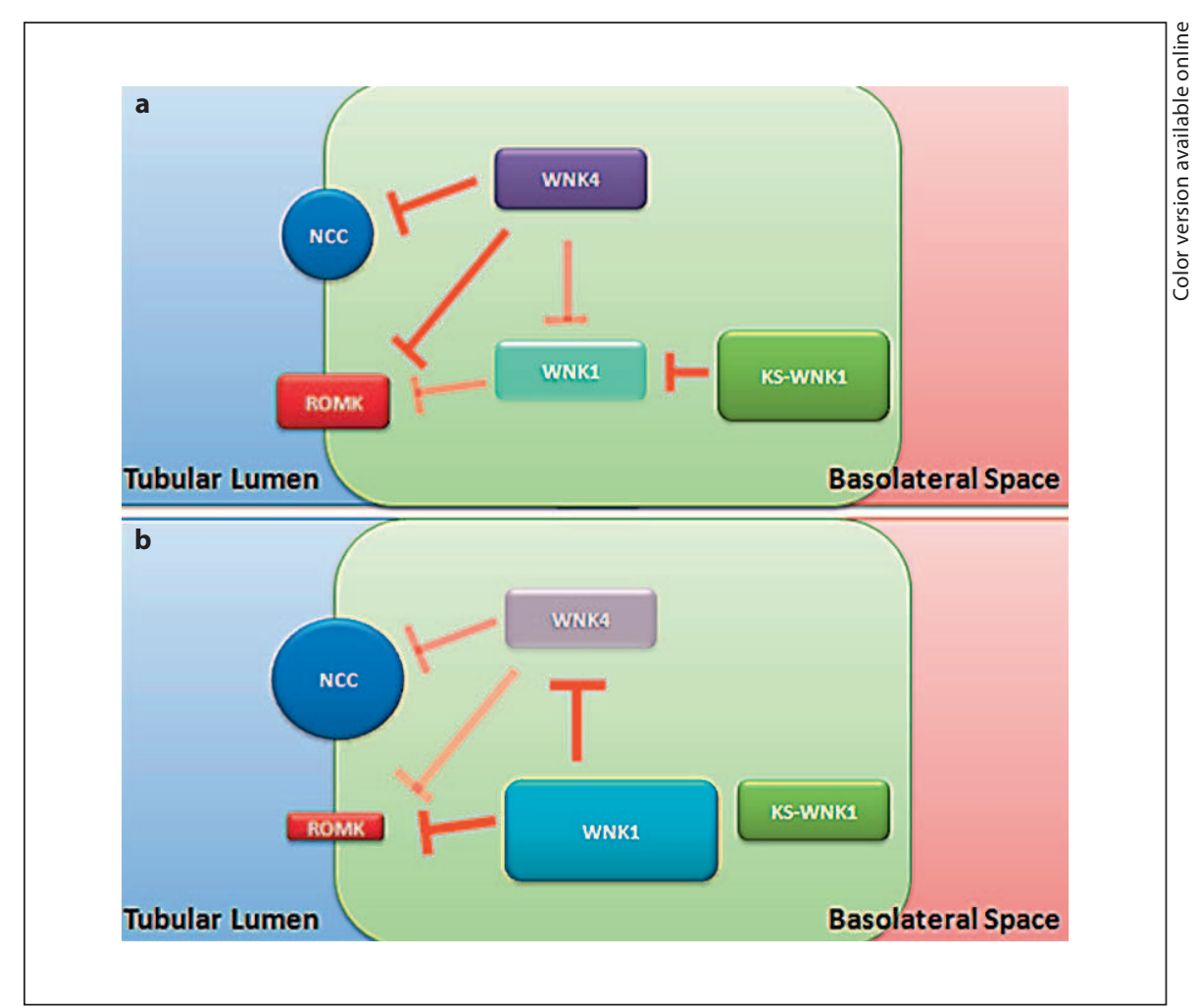

type. This is the extreme, pathophysiological version of what a regulated response to low blood volume should entail. In other words, WNK4 harboring PHA II mutations mimics the neuro-hormonal state required to retain volume in the face of intravascular volume depletion, in which the desired response is to retain salt and volume, without losing $\mathrm{K}^{+}$. Recent evidence supports that Ang II is an activator of NCC [37-39] and the observation that Ang II switches WNK4's behavior from an inhibitor to an activator of NCC [40], and further enhances the inhibition of ROMK by WNK4 [41] suggests that PHAII mutations in WNK4 are of the 'gain of function' type, mimicking the effect that Ang II has on NCC and ROMK. Thus, according to this model, PHAII with mutations in WNK4 could be viewed as the consequence of a state of 'hyperangiotensinism' localized to the distal nephron, not because Ang II is elevated, but because the DCT/CNT performs as if Ang II was permanently elevated.

In PHA II patients, due to overexpression of WNK1, the explanation of NCC activation and ROMK inhibition is the following: First, WNK1 directly inhibits ROMK [42-46]. Therefore, any increase in the expression of WNK1 leads to a dose dependent decrease in ROMK. Additionally, WNK1 is an inhibitor of WNK4, but this effect is in turn prevented by KS-WNK1, the short isoform which lacks the kinase domain and is expressed only in DCT (fig. 2). Under physiological conditions KS-WNK1 blunts the WNK1 effect on WNK4 and thus NCC is freely inhibited by WNK4 $[47,48]$. However, in PHA II patients, the augmented expression of WNK1 increases the ratio of WNK1/KS-WNK1 overcoming the inhibitory effect of KS-WNK1, allowing thus WNK1 to inhibit WNK4, leading to a WNK1-induced activation of NCC (fig. 2). Thus, hypertension in WNK1 PHAII patients seems to be also the consequence of increased activity of NCC in the DCT, similar to what happens in WNK4 PHA II patients and during hypovolemia.

Another member of the WNK kinase family that by itself can also mimic this neuro-hormonal state of salt retention without potassium excretion is WNK3. This kinase, which is expressed in DCT and CCD, activates NCC [49] and also inhibits ROMK [50]. The interaction/competition between WNK3 and WNK4 with regard to NCC is another potential mechanism for modulation of salt transport rate in DCT [51].

These rather complex mechanisms of transport regulation are starting to explain the complex clinical manifestations that are observed. In fact, by looking at the 
Table 1. Common clinical entities and the associated changes in aldosterone, Ang II, blood pressure, $\mathrm{Na}^{+}$balance and $\mathrm{K}^{+}$balance

\begin{tabular}{|c|c|c|c|c|c|c|}
\hline Clinical scenario & $\begin{array}{l}\text { Mineralocorticoid } \\
\text { activity }\end{array}$ & Ang II & $\begin{array}{l}\text { Change } \\
\text { in blood pressure }\end{array}$ & $\begin{array}{l}\mathrm{Na}^{+} \\
\text {balance }\end{array}$ & $\begin{array}{l}\mathrm{K}^{+} \\
\text {balance }\end{array}$ & Edema \\
\hline Hypovolemia & $\uparrow$ & $\uparrow$ & $\downarrow$ & $\uparrow$ & $\leftrightarrow$ & no \\
\hline (e.g. CHF, cirrhosis, etc.) & $\uparrow$ & $\uparrow$ & $\leftrightarrow$ & $\uparrow$ & $\leftrightarrow$ & yes \\
\hline High potassium diet & $\uparrow$ & $\downarrow$ & $\leftrightarrow$ & $\leftrightarrow$ & $\downarrow$ & no \\
\hline Primary hyperaldosteronism & $\uparrow$ & $\downarrow$ & $\uparrow$ & $\leftrightarrow$ & $\downarrow$ & no \\
\hline Addison's syndrome & $\downarrow$ & $\uparrow$ & $\downarrow$ & $\downarrow$ & $\uparrow$ & no \\
\hline
\end{tabular}

common underlying mechanisms, the kidney's response to various diseases becomes readily apparent (table 1). Diseases that present with low blood volume, be it by direct blood loss or extracellular fluid distribution abnormalities such as chronic heart failure, cirrhosis, nephrotic syndrome and others, have essentially the same underlying problem: decreased mean circulatory filling pressure and decreased urinary flow in the distal nephron. In these patients, the renin-angiotensin-aldosterone system is activated (secondary aldosteronism). Through the mechanisms described above (fig. 1), in secondary aldosteronism there is decreased flow in the distal nephron leading to a volume retentive state which attempts to increase circulating volume, without varying plasma $\mathrm{K}^{+}$. The decreased urinary flow in this part of the nephron favors $\mathrm{K}^{+}$retention by inhibiting the $\mathrm{BK}$ channels and indirectly inhibiting the $\mathrm{ENaC} / \mathrm{ROMK} \mathrm{Na} \mathrm{Na}^{+} / \mathrm{K}^{+}$exchange mechanism. Thus, in untreated patients that present with conditions where there is activation of both Ang II and aldosterone, there is an Ang II-WNK4 and aldosterone induced retention of $\mathrm{Na}^{+}$and volume, due to NCC and $\mathrm{ENaC}$ activation, but no change in plasma $\mathrm{K}^{+}$levels, because the aldosterone-induced increase in ROMK expression/activity is overcome by the Ang II-WNK4 and WNK1 reduction of ROMK activity, plus the reduced flow and delivery of salt to CNT/CD, due to the increased salt reabsorption in DCT. Because the increase in circulating volume comes at the expense of increasing $\mathrm{Na}^{+}$and water, which is not accompanied by a concomitant increase in oncotic pressure, this leads to fluid accumulation throughout the entire extracellular space which will clinically manifest itself as edema (table 1).

A completely different situation occurs when aldosterone is increased in the absence of activation of the renin-angiotensin-aldosterone system (fig. 1b). This is what occurs during a high potassium diet or primary aldosteronism, in which there is an increased flow rate in the distal nephron. Aldosterone increases the expression of the serum glucocorticoid kinase 1 (SGK1), which in turn phosphorylates and inhibits a protein known as Nedd4-2 that by ubiquitylating ENaC triggers the internalization and destruction of the channel. Thus, by inhibiting Nedd4-2, SGK1 induces and increase of ENaC expression in the plasma membrane [52]. In addition, by phosphorylating WNK4 in two critical sites, SGK1 will also prevent the WNK4-induced inhibition of ENaC and ROMK, thus releasing the activity of these channels, a condition that favors $\mathrm{K}^{+}$secretion through the $\mathrm{ENaC} / \mathrm{ROMK}$ exchange mechanism (see above) $[35,53]$. Aldosterone is also known to increase NCC protein expression [54], through regulation of Nedd4-2, a mechanism similar to that of ENaC [55]. Aldosterone mediated increase in NCC, however, would presumably be limited to DCT2, where the abundance of NCC is relatively minor, because DCT1 is not considered as part of the aldosterone sensitive distal nephron due to the absence of $11 \beta$-hydroxysteroid dehydrogenase type 2 that precludes the promiscuous occupation of the mineralocorticoid receptor by cortisol $[22,56]$. Hence, although NCC expression is increased in DCT2 in a state of isolated aldosterone secretion, because of the absence of the Ang II, NCC in DCT1 would remain under WNK4 inhibition. This results in increased distal delivery of $\mathrm{Na}^{+}$ and volume and activation of $\mathrm{ENaC}, \mathrm{ROMK}$ and $\mathrm{BK}$ channels leading to an increase in of the $\mathrm{Na}^{+} / \mathrm{K}^{+}$exchange and thus increased $\mathrm{K}^{+}$excretion. This phenomenon becomes clinically relevant in states of increased aldosterone secretion with decreased activity of Ang II and a consequent increased flow in the distal nephron (table 1). The day-to-day scenario that emulates this situation is the high $\mathrm{K}^{+}$diet where salt reabsorption in DCT1 is decreased, allowing the $\mathrm{Na}^{+} / \mathrm{K}^{+}$exchange in 
$\mathrm{CD}$ to secrete the excess $\mathrm{K}^{+}$. A pathophysiological version is primary aldosteronism, where an autonomous increase of aldosterone promotes sodium reabsorption and $\mathrm{K}^{+}$secretion by increasing the activity of $\mathrm{ENaC}$ and ROMK, respectively. Why these patients do not develop edema, similarly to what happens in patients with secondary hyperaldosteronism, is due to the presence versus absence of Ang II in secondary versus primary aldosteronism. In secondary aldosteronism, as discussed above, Ang II, presumably via WNK4 activates NCC. In contrast, in primary aldosteronism, the fact that NCC is not activated by aldosterone in DCT1 suggests that these patients are still subject to pressure natriuresis. In fact, although NCC is considered to be an aldosterone-regulated protein [54], during the aldosterone-escape phenomenon, of all the studied transporters in the kidney, NCC is the only one whose expression is actually decreased, despite the continuous administration of aldosterone [57]. Thus, in primary aldosteronism, the reduced activity of NCC in DCT1 keeps the salt balance and because of the increased flow rate provides the salt and volume delivery to CNT/CD producing hypokalemia. In other words, the inhibition of NCC in DCT1 is enough to overcome the $\mathrm{ENaC}$ activity, at least to prevent the edema formation, but at the expense of arterial hypertension. This mechanism extends to Cushing's syndrome. When the elevated cortisol in plasma overcomes the capacity of the $11 \beta$-hydroxysteroid dehydrogenase type 2 to degrade it and thus, occupies and activates the mineralocorticoid receptor, as if aldosterone was increased. A similar situation occurs in Liddle's syndrome in which there is a primary increase in $\mathrm{ENaC}$ activity due to mutations in the $\beta$ or $\gamma$ subunits of $\mathrm{ENaC}$ that eliminate the PY motif required for Nedd4-2 and
$\mathrm{ENaC}$ interaction, thus precluding the normal regulation of the channel by Nedd4-2 [58]. The clinical picture of Liddle's syndrome is similar to primary aldosteronism: hypertension with hypokalemia. The increased sodium absorption by ENaC induces hypertension and by pressure natriuresis mechanisms NCC must be inhibited to maintain salt balance, preventing edema formation.

In summary, the integration of the renal molecular mechanisms that are regulated via the WNK kinases has now shed light on an issue that remained obscure for long time. The molecular mechanisms of the interaction between aldosterone and Ang II in the differentiation between volume retention and $\mathrm{K}^{+}$secretion are beginning to be elucidated, providing a better molecular understanding of physiological or pathophysiological processes associated with classical clinical syndromes of salt and potassium metabolism.

\section{Acknowledgements}

We thank Paul Kimmel, MD, for his critical reading of the manuscript. This work was supported in part by the Leducq Foundation Transatlantic Network on Hypertension and El Consejo Nacional de Ciencia y Tecnología (CONACYT-Mexico) Grant 165815 (to G.G.). J.P.A. was supported by a scholarship from CONACYT-Mexico and is a graduate student in the Biomedical Science PhD Program of the Universidad Nacional Autónoma de México, UNAM.

\section{Disclosure Statement}

No conflicts of interest are declared

\section{References}

1 Hoorn EJ, Nelson, JH, McCormick, JA, Ellison, DH: The WNK Kinase Network Regulating Sodium, Potassium, and Blood Pressure. J Am Soc Nephrol 2011;22:605-614.

2 McCormick JA, Ellison DH: The WNKs: atypical protein kinases with pleiotropic actions. Physiol Rev 2011;91:177-219.

3 Wilson FH, Disse-Nicodeme S, Choate KA, Ishikawa K, Nelson-Williams C, Desitter I, Gunel M, Milford DV, Lipkin GW, Achard JM, Feely MP, Dussol B, Berland Y, Unwin RJ, Mayan H, Simon DB, Farfel Z, Jeunemaitre X, Lifton RP: Human hypertension caused by mutations in WNK kinases. Science 2001;293:1107-1112.
4 Mayan H, Vered I, Mouallem M, TzadokWitkon M, Pauzner R, Farfel Z: Pseudohypoaldosteronism type II: marked sensitivity to thiazides, hypercalciuria, normomagnesemia, and low bone mineral density. J Clin Endocrinol Metab 2002;87:3248-3254.

5 Gordon RD, Hodsman GP: The syndrome of hypertension and hyperkalaemia without renal failure: long term correction by thiazide diuretic. Scott Med J 1986;31:43-44.

6 Gamba G: The thiazide-sensitive $\mathrm{Na}^{+}-\mathrm{Cl}^{-}$ cotransporter: molecular biology, functional properties, and regulation by WNKs. Am J Physiol Renal Physiol 2009;297:F838F848.
7 Simon DB, Nelson-Williams C, Johnson-Bia M, Ellison D, Karet FE, Morey-Molina A, Vaara I, Iwata F, Cushner HM, Koolen M, Gainza FJ, Gitelman HJ, Lifton RP: Gitelman's variant of Bartter's syndrome, inherited hypokalaemic alkalosis, is caused by mutations in the thiazide-sensitive $\mathrm{Na}-\mathrm{Cl}$ cotransporter. Nat Genet 1996;12:24-30.

-8 Plotkin MD, Kaplan MR, Verlander JM, Lee W-S, Brown D, Poch E, Gullans SR, Hebert SC: Localization of the thiazide sensitive $\mathrm{Na}$ $\mathrm{Cl}$ cotransporter, rTSC1, in the rat kidney. Kidney Int 1996;50:174-183. 
9 Loffing J, Vallon V, Loffing-Cueni D, Aregger F, Richter K, Pietri L, Bloch-Faure M, Hoenderop JG, Shull GE, Meneton P, Kaissling B: Altered renal distal tubule structure and renal $\mathrm{Na}^{+}$and $\mathrm{Ca}^{2+}$ handling in a mouse model for Gitelman's syndrome. J Am Soc Nephrol 2004;15:2276-2288.

10 Bachmann S, Velázquez $\mathrm{H}$, Obermuller $\mathrm{N}$, Reily RF, Moser D, Ellison DH: Expression of the thiazide-sensitive $\mathrm{Na}-\mathrm{Cl}$ cotransporter by rabbit distal convoluted tubule cells. J Clin invest 1995;96:2510-2514.

11 Wilson FH, Kahle KT, Sabath E, Lalioti MD, Rapson AK, Hoover RS, Hebert SC, Gamba G, Lifton RP: Molecular pathogenesis of inherited hypertension with hyperkalemia: the $\mathrm{Na}-\mathrm{Cl}$ cotransporter is inhibited by wildtype but not mutant WNK4. Proc Natl Acad Sci USA 2003;100:680-684.

-12 Arroyo JP, Ronzaud C, Lagnaz D, Staub O, Gamba G: Aldosterone paradox: differential regulation of ion transport in distal nephron. Physiology (Bethesda) 2011;26:115-123.

-13 Reilly RF, Ellison DH: Mammalian distal tubule: physiology, pathophysiology, and molecular anatomy. Physiol Rev 2000;80:277313.

14 Loffing J, Loffing-Cueni D, Valderrabano V, Klausli L, Hebert SC, Rossier BC, Hoenderop JG, Bindels RJ, Kaissling B: Distribution of transcellular calcium and sodium transport pathways along mouse distal nephron. Am J Physiol Renal Physiol 2001;281:F1021-F1027.

15 Biner HL, Arpin-Bott MP, Loffing J, Wang X, Knepper M, Hebert SC, Kaissling B: Human cortical distal nephron: distribution of electrolyte and water transport pathways. J Am Soc Nephrol 2002;13:836-847.

16 Ellison DH, Velazquez H, Wright FS: Thiazide-sensitive sodium chloride cotransport in early distal tubule. Am J Physiol Renal Fluid Electrolyte Physiol 1987;253:F546F554.

17 Loffing J, Kaissling B: Sodium and calcium transport pathways along the mammalian distal nephron: from rabbit to human. Am J Physiol Renal Physiol 2003;284:F628-F643.

$\checkmark 18$ Amorim JB, Bailey MA, Musa-Aziz R, Giebisch G, Malnic G: Role of luminal anion and $\mathrm{pH}$ in distal tubule potassium secretion. Am J Physiol Renal Physiol 2003;284:F381F388.

$\checkmark 19$ Hebert SC, Desir G, Giebisch G, Wang W: Molecular diversity and regulation of renal potassium channels. Physiol Rev 2005;85: 319-371.

20 Grimm PR, Sansom SC: BK channels and a new form of hypertension. Kidney Int 2010; 78:956-962.

-21 O’Reilly M, Marshall E, Macgillivray T, Mittal M, Xue W, Kenyon CJ, Brown RW: Dietary electrolyte-driven responses in the renal WNK kinase pathway in vivo. J Am Soc Nephrol 2006;17:2402-2413.
22 Bachmann S, Bostanjoglo M, Schmitt R, Ellison $\mathrm{DH}$ : Sodium transport-related proteins in the mammalian distal nephron - distribution, ontogeny and functional aspects. Anat Embryol (Berl) 1999;200:447-468.

23 Piechotta K, Lu J, Delpire E: Cation chloride cotransporters interact with the stress-related kinases Ste20-related proline-alaninerich kinase (SPAK) and oxidative stress response 1 (OSR1). J Biol Chem 2002;277: 50812-50819.

24 Vitari AC, Deak M, Morrice NA, Alessi DR: The WNK1 and WNK4 protein kinases that are mutated in Gordon's hypertension syndrome, phosphorylate and active SPAK and OSR1 protein kinases. Biochem J 2005;391: $17-24$.

25 Rafiqi FH, Zuber AM, Glover M, Richardson C, Fleming S, Jovanovic S, Jovanovic A, O'Shaughnessy KM, Alessi DR: Role of the WNK-activated SPAK kinase in regulating blood pressure. EMBO Mol Med 2010;2:6375.

26 Frindt G, Palmer LG: Effects of dietary K on cell-surface expression of renal ion channels and transporters. Am J Physiol Renal Physiol 2010;299:F890-F897.

27 Woda CB, Bragin A, Kleyman TR, Satlin LM: Flow-dependent $\mathrm{K}^{+}$secretion in the cortical collecting duct is mediated by a maxi-K channel. Am J Physiol Renal Physiol 2001; 280:F786-F793.

28 Krishna GG, Shulman MD, Narins RG: Clinical use of the potassium-sparing diuretics. Semin Nephrol 1988;8:354-364.

29 Rose BD: Diuretics. Kidney Int 1991;39:336 352.

-30 Appel LJ, Moore TJ, Obarzanek E, Vollmer WM, Svetkey LP, Sacks FM, Bray GA, Vogt TM, Cutler JA, Windhauser MM, Lin PH, Karanja N: A clinical trial of the effects of dietary patterns on blood pressure. DASH Collaborative Research Group. N Engl J Med 1997;336:1117-1124.

31 Sacks FM, Svetkey LP, Vollmer WM, Appel LJ, Bray GA, Harsha D, Obarzanek E, Conlin PR, Miller ER III, Simons-Morton DG, Karanja N, Lin PH: Effects on blood pressure of reduced dietary sodium and the Dietary Approaches to Stop Hypertension (DASH) diet. DASH-Sodium Collaborative Research Group. N Engl J Med 2001;344:3-10.

32 Huang CL, Kuo E: Mechanisms of disease: WNK-ing at the mechanism of salt-sensitive hypertension. Nat Clin Pract Nephrol 2007; 3:623-630.

33 Frindt G, Houde V, Palmer LG: Conservation of $\mathrm{Na}^{+} \mathrm{vs}$. $\mathrm{K}^{+}$by the rat cortical collecting duct. Am J Physiol Renal Physiol 2011; 301:F14-F20.

34 Kahle KT, Wilson FH, Leng Q, Lalioti MD, O'Connell AD, Dong K, Rapson AK, MacGregor GG, Giebisch G, Hebert SC, Lifton $\mathrm{RP}$ : WNK4 regulates the balance between renal $\mathrm{NaCl}$ reabsorption and $\mathrm{K}^{+}$secretion. Nat Genet 2003;35:372-376.
5 Ring AM, Cheng SX, Leng Q, Kahle KT, Rinehart J, Lalioti MD, Volkman HM, Wilson FH, Hebert SC, Lifton RP: WNK4 regulates activity of the epithelial $\mathrm{Na}^{+}$channel in vitro and in vivo. Proc Natl Acad Sci USA 2007;104:4020-4024.

-36 San Cristobal P, De Los HP, Ponce-Coria J, Moreno E, Gamba G: WNK kinases, renal ion transport and hypertension. Am J Nephrol 2008;28:860-870.

37 Sandberg MB, Riquier AD, PihakaskiMaunsbach K, McDonough AA, Maunsbach AB: Angiotensin II provokes acute trafficking of distal tubule $\mathrm{NaCl}$ cotransporter (NCC) to apical membrane. Am J Physiol Renal Physiol 2007;293:F662-F669.

- 38 van der LN, Lim CH, Fenton RA, Meima ME, Jan Danser AH, Zietse R, Hoorn EJ: Angiotensin II induces phosphorylation of the thiazide-sensitive sodium chloride cotransporter independent of aldosterone. Kidney Int 2011;79:66-76.

39 Zhao D, Seth DM, Navar LG: Enhanced distal nephron sodium reabsorption in chronic angiotensin II-infused mice. Hypertension 2009;54:120-126.

40 San Cristobal P, Pacheco-Alvarez D, Richardson C, Ring AM, Vazquez N, Rafiqi FH, Chari D, Kahle KT, Leng Q, Bobadilla NA, Hebert SC, Alessi DR, Lifton RP, Gamba G: Angiotensin II signaling increases activity of the renal $\mathrm{Na}-\mathrm{Cl}$ cotransporter through a WNK4-SPAK-dependent pathway. Proc Natl Acad Sci USA 2009;106:4384-4389.

-41 Yue P, Sun P, Lin DH, Pan C, Xing W, Wang $\mathrm{W}$ : Angiotensin II diminishes the effect of SGK1 on the WNK4-mediated inhibition of ROMK1 channels. Kidney Int 2011;79:423431.

42 Cheng CJ, Huang CL: Activation of PI3-kinase stimulates endocytosis of ROMK via Akt1/SGK1-dependent phosphorylation of WNK1. J Am Soc Nephrol 2011;22:460-471.

$\checkmark 43 \mathrm{He}$ G, Wang HR, Huang SK, Huang CL: Intersectin links WNK kinases to endocytosis of ROMK1. J Clin Invest 2007;117:10781087.

44 Huang CL, Yang SS, Lin SH: Mechanism of regulation of renal ion transport by WNK kinases. Curr Opin Nephrol Hypertens 2008; 17:519-525.

45 Lazrak A, Liu Z, Huang CL: Antagonistic regulation of ROMK by long and kidneyspecific WNK1 isoforms. Proc Natl Acad Sci USA 2006; 103:1615-1620.

46 Liu Z, Wang HR, Huang CL: Regulation of ROMK channel and $\mathrm{K}^{+}$homeostasis by kidney-specific WNK1 kinase. J Biol Chem 2009;284:12198-12206.

47 Subramanya AR, Yang CL, Zhu X, Ellison $\mathrm{DH}$ : Dominant-negative regulation of WNK1 by its kidney-specific kinase-defective isoform. Am J Physiol Renal Physiol 2006;290:F619-F624. 
48 Liu Z, Xie J, Wu T, Truong T, Auchus RJ, Huang CL: Downregulation of NCC and NKCC2 cotransporters by kidney-specific WNK1 revealed by gene disruption and transgenic mouse models. Hum Mol Genet 2011;20:855-866.

-49 Rinehart J, Kahle KT, De Los HP, Vazquez N, Meade P, Wilson FH, Hebert SC, Gimenez I, Gamba G, Lifton RP: WNK3 kinase is a positive regulator of NKCC2 and NCC, renal cation- $\mathrm{Cl}$ cotransporters required for normal blood pressure homeostasis. Proc Natl Acad Sci USA 2005;102:16777-16782.

50 Leng Q, Kahle KT, Rinehart J, MacGregor GG, Wilson FH, Canessa CM, Lifton RP, Hebert SC: WNK3, a kinase related to genes mutated in hereditary hypertension with hyperkalaemia, regulates the $\mathrm{K}^{+}$channel ROMK1 (Kir1.1). J Physiol 2006;571:275286.
Yang CL, Zhu X, Ellison DH: The thiazidesensitive $\mathrm{Na}-\mathrm{Cl}$ cotransporter is regulated by a WNK kinase signaling complex. J Clin Invest 2007;117:3403-3411.

52 Abriel H, Staub O: Ubiquitylation of ion channels. Physiology (Bethesda) 2005;20: 398-407.

53 Ring AM, Leng Q, Rinehart J, Wilson FH, Kahle KT, Hebert SC, Lifton RP: An SGK1 site in WNK4 regulates $\mathrm{Na}^{+}$channel and $\mathrm{K}^{+}$ channel activity and has implications for aldosterone signaling and $\mathrm{K}^{+}$homeostasis. Proc Natl Acad Sci USA 2007;104:40254029.

54 Kim G-H, Masilamani S, Turner R, Mitchell C, Wade JB, Knepper MA: The thiazide-sensitive $\mathrm{Na}-\mathrm{Cl}$ cotransporter is an aldosteroneinduced protein. Proc Natl Acad Sci USA 1998;95:14552-14557.

55 Arroyo JP, Lagnaz D, Ronzaud C, Vazquez N, Ko BS, Moddes L, Ruffieux-Dadidié D, Hausel P, Koesters R, Yang B, Stokes JB, Hoover RS, Gamba G, Staub O: Nedd4-2 modulates renal $\mathrm{Na}^{+-} \mathrm{Cl}^{-}$cotransporter via the aldosterone-SGK1-Nedd4-2 pathway. J Am Soc Nephrol 2011;22:1707-1719.
56 Bostanjoglo M, Reeves WB, Reilly RF, Velazquez H, Robertson N, Litwack G, Morsing P, Dorup J, Bachmann S, Ellison DH, Bostonjoglo M: 11Beta-hydroxysteroid dehydrogenase, mineralocorticoid receptor, and thiazide-sensitive $\mathrm{Na}-\mathrm{Cl}$ cotransporter expression by distal tubules. J Am Soc Nephrol 1998;9:1347-1358.

57 Wang XY, Masilamani S, Nielsen J, Kwon TH, Brooks HL, Nielsen S, Knepper MA: The renal thiazide-sensitive $\mathrm{Na}-\mathrm{Cl}$ cotransporter as mediator of the aldosterone-escape phenomenon. J Clin Invest 2001;108:215-222.

58 Shimkets RA, Warnock DG, Bositis CM, Nelson-Williamns C, Hansson JH, Schambelan M, Gill JR, Ulick S, Milora RV, Findling JW, Canessa CM, Rossier BC, Lifton RP: Liddle's syndrome: heritable human hypertension caused by mutations in the beta subunit of the epithelial sodium channel. Cell 1994;79:407-414. 